\title{
Resistin expression and plasma concentration peak at different times during pregnancy in rats
}

\author{
Sergio Caja, Izaskun Martínez, María Abelenda \\ and Marisa Puerta
}

Department of Animal Physiology II, Faculty of Biological Sciences, Complutense University, 28040 Madrid, Spain

(Requests for offprints should be addressed to M Puerta; Email: mpuerta@bio.ucm.es)

\begin{abstract}
Resistin has been proposed as both an anti-adipogenic factor and an inducer of insulin resistance. During late pregnancy, white adipose tissue mass increases and insulin sensitivity decreases. To check for the involvement of resistin in these processes, we measured plasma resistin in pregnant and non-pregnant rats and in lactating dams. Plasma resistin increased by day 15 of pregnancy and remained high 5 days post partum. The simultaneous increase in plasma resistin concentration and the decrease in insulin sensitivity is compatible with resistin depressing maternal insulin sensitivity. Resistin expression increased 5-15 times in visceral white adipose tissue depots by day 8 of pregnancy but was similar to pre-pregnancy values by day 19. Resistin expression in the placenta and mammary
\end{abstract}

gland was similar to that in the parametrial adipose depot by day 8 but was almost null by day 19. There was therefore a time-lag between the peaks in expression and in plasma concentration. White adipose tissue mass increased without changes in adipocyte size once peaks in resistin expression had passed, which is compatible with an anti-adipogenic role for enhanced resistin expression. A bolus injection of chorionic gonadotrophin - which peaks in early pregnancy - to non-pregnant rats increased resistin expression in white adipose tissue, indicating that this hormone is involved in controlling resistin expression. Resistin was not detected in cerebrospinal fluid. Our results have suggested a role for resistin in pregnancy.

Journal of Endocrinology (2005) 185, 551-559

\section{Introduction}

The traditional view of white adipose tissue (WAT) as a passive lipid storage organ has changed to a broader perspective following the recognition that white adipocytes release a wide range of signalling molecules. The physiological significance of many of these signalling molecules remains unknown (Frühbeck et al. 2001, Trayhurn \& Beattie 2001, Guerre-Millo 2004). One of these bioactive peptides, collectively termed adipokines, is resistin. Resistin was originally described as FIZZ3 (Holcomb et al. 2000). Soon afterwards, Kim et al. (2001) identified it as an adipocyte-secreted factor that inhibits adipocyte differentiation in vitro. Simultaneously, Steppan et al. (2001) proposed it as a factor in the development of insulin resistance and renamed it resistin. This followed the observation that increases in expression and plasma levels occur in several models of obesity while the immunoneutralisation of plasma resistin with specific antibodies or a decrease in plasma levels with thiazolidinediones improved insulin action (Steppan et al. 2001). Moreover, administration of resistin to mice or rats induces insulin resistance (Steppan et al. 2001, Rajala et al. 2003). However, the contrasting observation of diminished resistin expression in the WAT of obese animals (Juan et al. 2001, Le Lay et al. 2001, Moore et al. 2001, Way et al. 2001, Fujita et al. 2002, Milan et al. 2002) together with the inhibition of expression by insulin in 3T3-L1 cells (Haugen et al. 2001, Shojima et al. 2002) has cast doubt on the role of resistin in the development of insulin resistance. Additionally, in some physiological states related with an altered insulin sensitivity, no changes in resistin expression have been found (Bing et al. 2002, Gomez-Ambrosi et al. 2002, Puerta et al. 2002). Nonetheless, mice lacking resistin show reduced hepatic glucose production, suggesting a role for resistin in glucose metabolism (Banerjee et al. 2004).

During pregnancy, maternal and foetal growth is enabled by a substantial increase in food intake and substrate re-partitioning (Abelenda \& Puerta 1987, Herrera et al. 2000). To this end, maternal insulin sensitivity evolves from an enhanced state during early pregnancy, allowing maternal growth, to an insulin-resistant state in late pregnancy, diverting substrates away from the mother for foetal growth. This latter 'catabolic state' (for the mother) is present during the last third of pregnancy (Leturque et al. 1986, 1987). Pregnancy is therefore a suitable model for studying natural changes in insulin sensitivity and the 
related endocrine factors. On the other hand, WAT depots increase their mass during pregnancy (Rocha et al. 2003), so it is also a suitable model for studying adipogenesis. The aim of this paper was to test whether resistin expression or plasma concentration change during pregnancy and, if so, to relate those changes to corresponding alterations in insulin sensitivity and WAT mass.

\section{Materials and Methods}

\section{Animals}

Female Wistar rats weighing 180-200 g were housed at $22{ }^{\circ} \mathrm{C}$ in individual cages, with water and food (A04, Panlab, Barcelona, Spain) freely available and with a $12 \mathrm{~h}$ light: $12 \mathrm{~h}$ darkness cycle (lights on at $0800 \mathrm{~h}$ ). The stage of the oestrous cycle was assessed daily to determine the reproductive status of the animals. To obtain pregnant animals or dams, a female was housed with a male for $4 \mathrm{~h}$ on the morning of oestrus. Mating was indicated by the presence of sperm in the vaginal smears. The day of mating was considered day 0 of pregnancy. Non-pregnant rats at di-oestrus were used to represent day 0 of pregnancy. Animals were cared for and used in accordance with the principles of the Council of European Communities (86/ 609 EEC).

\section{Sample collection}

At days 0, 8, 15 and 19 of pregnancy, animals were killed by decapitation between 1000 and 1200 h. Just before they were killed, cerebrospinal fluid (CSF) was obtained under halothane anaesthesia by inserting a 23 gauge butterfly needle into the cisterna magna. Only samples with no blood contamination were processed. Trunk blood was collected at the time of decapitation, allowed to clot, centrifuged to obtain serum and stored at $-80{ }^{\circ} \mathrm{C}$ until analysis.

Samples of parametrial, retroperitoneal and subcutaneous WAT depots from the left side of the animals were quickly removed, frozen in liquid $\mathrm{N}_{2}$ and stored at $-80{ }^{\circ} \mathrm{C}$ until analysis of resistin expression. A piece of parametrial WAT was immersed in Bouin's fluid for histological examination. The corresponding right-side WAT depots together with the inguinal, periovaric and perirenal depots were also removed and weighed.

In 8- and 19-day pregnant rats, pieces of placenta and mammary gland were also quickly removed and frozen in liquid $\mathrm{N}_{2}$. In 8-day pregnant rats, the placenta is not fully developed so, for the purposes of comparison, the whole embryo together with the extra-embryonic membranes and the surrounding uterine wall were also collected and frozen. These tissues together are referred to as placenta in the rest of the paper.

A group of pregnant rats was allowed to deliver and a sample of blood from the jugular vein was collected under halothane anaesthesia at day 5 post partum. Pups were weaned at day 21 and a blood sample was again obtained at days 22 and 30 post partum.

\section{Hormonal administration}

A single i.p. injection of human chorionic gonadotrophin (hCG; Sigma, St Louis, MO, USA) was given to a group of non-pregnant rats in di-oestrous II at 0900-0930 h. They were killed 8 or $24 \mathrm{~h}$ later. Each animal received 200 IU in $140 \mu \mathrm{l}$ phosphate-buffered saline. Controls received a similar volume of vehicle.

\section{$m R N A$ detection}

WAT, placenta and mammary gland samples were homogenised in Ultraspec reagent (Biotecx Laboratories, Houston, TX, USA) to obtain total cellular RNA, based on the single-step method of Chomczynski \& Sacchi (1987). The procedures used for the fractionation, blotting and hybridisation of mRNAs together with a chemiluminescence detection protocol were carried out as described previously (Trayhurn et al. 1994). In outline, RNAs were fractionated by agarose electrophoresis gel, transferred to a positively charged nylon membrane (Roche, Mannheim, Germany) by capillary blotting and cross-linked under u.v. light. Resistin mRNA was detected using a specific antisense oligonucleotide end-labelled $5^{\prime}$ with digoxigenin (Oswel, Southampton, Hampshire, UK) as previously described (Puerta et al. 2002). The membranes were incubated sequentially with the oligonucleotide and with an anti-digoxigenin $\mathrm{FAB} /$ alkaline phosphatase conjugate (Roche) and then processed essentially as described in the protocols provided by the manufacturer. CDP-star (Roche) was used as the chemiluminescence substrate. Signals were obtained by X-ray film exposure of the membrane (Hyperfilm ECL; Amersham Pharmacia Biotech, Amersham, Bucks, UK). Membranes were stripped and reprobed for $18 \mathrm{~S}$ rRNA to adjust for any differences in the loading and transfer of RNA during blotting. 18S rRNA was detected using a 31-mer antisense oligonucleotide probe, as previously described (Trayhurn et al. 1995).

\section{Histology}

WAT samples were placed in Bouin's fluid for $48 \mathrm{~h}$ and then stored in $70 \%$ alcohol at $4{ }^{\circ} \mathrm{C}$. After dehydration with increasing alcohol concentrations they were embedded in paraffin and sliced into $70 \mu \mathrm{m}$ sections. They were stained with sequential immersion in haematoxylin and eosin. Adipocyte surface was measured in 150 cells from the same individual using the MetaMorph program (Universal Imaging Corp., Downington, PA, USA).

\section{Serum and CSF resistin}

Resistin concentration was measured with the human enzyme immunoassay kit developed by Phoenix 
Pharmaceuticals, Inc. (Belmont, CA, USA) which according to the manufacturer - recognises rat resistin. Parallelism was tested and the results agreed with both the manufacturer and previous reports using the kit in rats (Chen \& Nyomba 2003). Serum was assayed as it was obtained. CSF was assayed either as it was obtained or after being lyophilised and re-dissolved in a 2 times smaller volume of buffer kit.

\section{Insulin tolerance test (ITT)}

Rats fasted for $2 \mathrm{~h}$ were injected i.p. with insulin (human insulin; 0.2 IU/100 g body weight; Lilly, Alcobendas, Spain) between 1200 and $1300 \mathrm{~h}$. Blood samples (50$60 \mu \mathrm{l}$ ) were collected by tail snip at $0 \mathrm{~min}$ (just before insulin injection) and at 15, 30, 45, 60 and 120 min after injection. Serum was immediately separated and glucose analysed with the GOD-POD method by using diagnostic reagent kit (Spinreact, St Esteve de Bas, Gerona, Spain). The glucose disappearance rate $\left(K_{\text {ITT }}\right)$ was calculated using the formula $0.693\left(t_{1 / 2}\right)$ (Lundbaek 1962). The plasma glucose half-life $\left(t_{1 / 2}\right)$ was calculated from the slope of the least-square analysis of the plasma glucose concentration during the linear decay phase. A high degree of correlation between the ITT and clamp studies used to determine insulin sensitivity has been shown previously (Bonora et al. 1989).

\section{Statistical analysis}

One-way ANOVA with time of pregnancy as a factor non-pregnant rats representing day 0 of pregnancy - was used for comparing $K_{\text {ITT }}$, WAT depot mass and plasma resistin during pregnancy, adipocyte size and the optical density of the bands corresponding to resistin in Northern blots. A Student-Newman-Keuls (SKN) test was used for post hoc comparisons. One-way ANOVA was also used to analyse the effects of hCG administration. A two-way ANOVA for repeated measures was used for comparing body weight of pregnant and non-pregnant animals (pregnancy and time were the between-subject factor and within-subject factor respectively). Pair wise comparisons were done according to the Bonferroni method. Plasma resistin in dams was analysed by one-factor within-subjects ANOVA. Pair wise comparisons were done according to the Bonferroni method. $P<0 \cdot 05$ was considered statistically significant throughout. In the Figures and Tables, differences have been indicated by a superscript so that data with an 'a' are different from those with a 'b' but are the same as 'a,b'.

\section{Results}

From early pregnancy (day 8), pregnant rats showed a greater body weight gain than non-pregnant animals

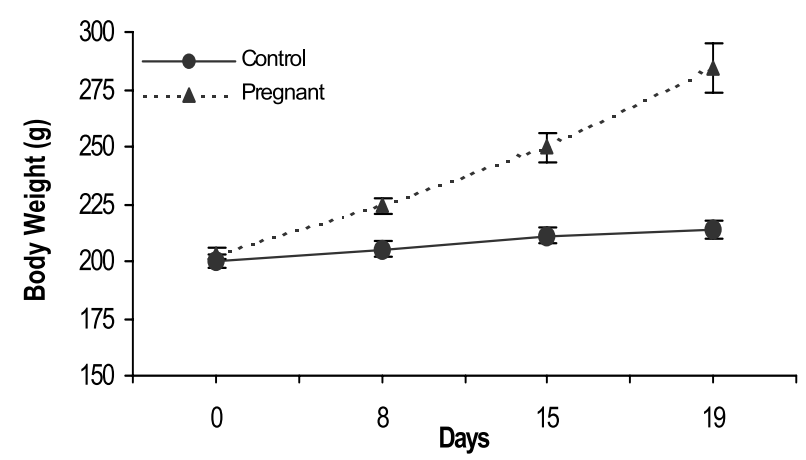

Figure 1 Changes in body weight during pregnancy. A group of non-pregnant rats with similar body weight at the beginning of the experiment was used as control. Data are expressed as mean values \pm S.E.M. of eight animals. A two-way ANOVA for repeated measures revealed $P<0.000$ for pregnancy and for time with pair wise comparisons done by the Bonferroni method.

(Fig. 1). The number of foetuses was 6-14. Figure 2 shows that insulin sensitivity - as deduced from the glucose disappearance rate after an insulin injection - changed during pregnancy, as expected. Thus, $K_{\text {ITT }}$ was higher by day 8 than by day 0 . Later on, it decreased to reach the lowest level by day 19 .
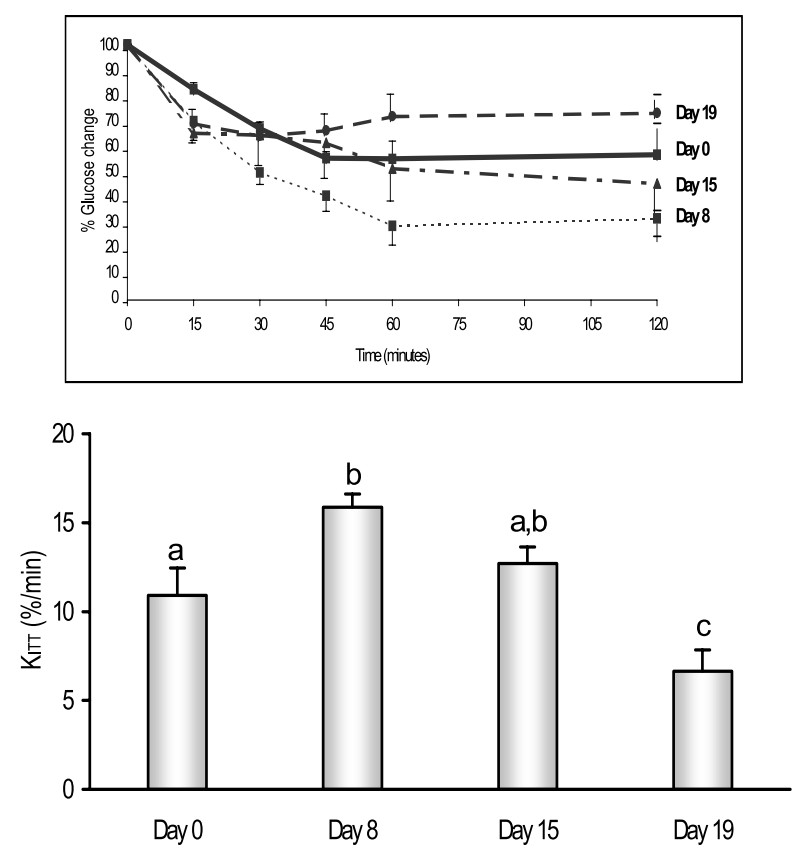

Figure $2 K_{\mathrm{ITT}}$ after an i.p. insulin injection in non-pregnant (day 0) and pregnant rats at different times during pregnancy. Bars represent the mean \pm S.E.M. of five to seven animals. Different superscript letters mean $P<0 \cdot 05$ when analysed by a one-way ANOVA using the SNK test for post hoc comparisons. The insert shows the time-course of the changes in plasma glucose concentration indicated as \% of the initial concentration (such initial values were $138 \pm 8,129 \pm 8,98 \pm 4$ and $86 \pm 3 \mathrm{mg} / \mathrm{ml}$ for days $0,8,15$ and 19 respectively). 


\section{a. Inguinal}

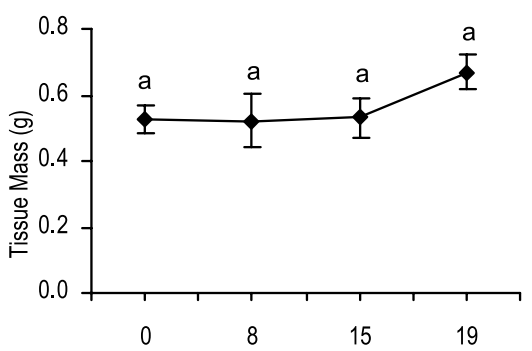

b. Parametrial

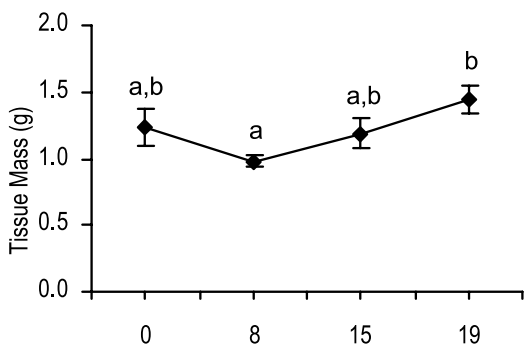

\section{c. Retroperitoneal}

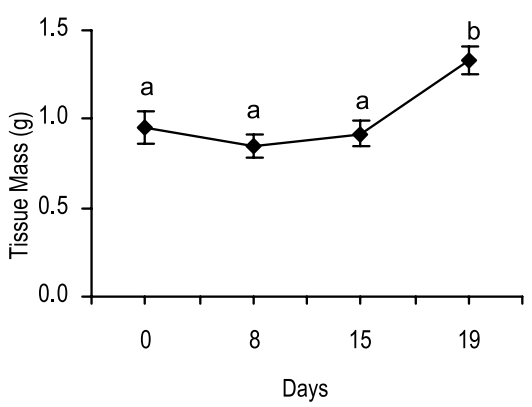

\section{d. Periovaric}

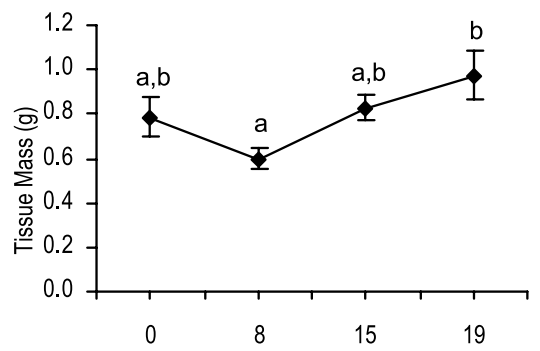

e. Perirenal

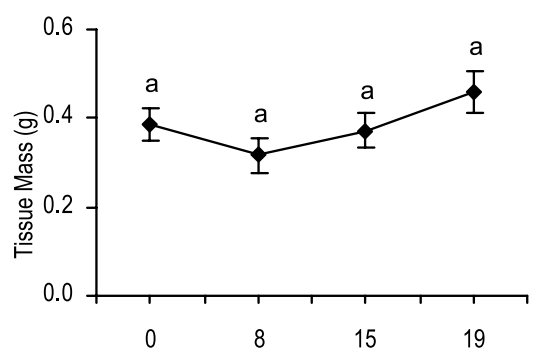

\section{f. Total}

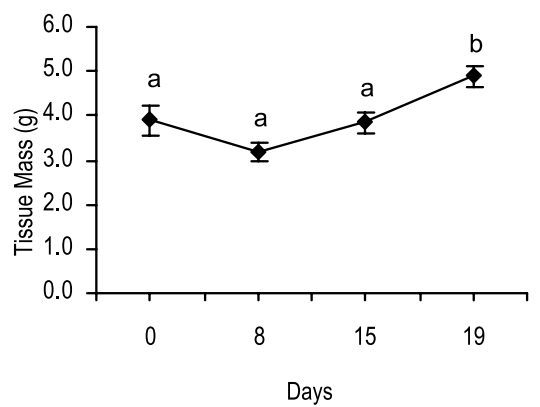

Figure 3 Changes in fat mass in visceral WAT depots in non-pregnant (day 0) and pregnant rats at different times during pregnancy. Each point represents the mean \pm S.E.M. of eight rats. Different superscript letters mean $P<0.05$ when analysed by a one-way ANOVA using the SNK test for post hoc comparisons.

Changes in main fat pad mass are depicted in Fig. 3 which shows how, during the first 15 days of pregnancy, there were no significant increases in fat mass in the five WAT depots considered. However, during the last 4 days considered - an interval of 15-19 days - there was a trend to increased fat mass. The increase reached statistical differences in parametrial, periovaric and retroperitoneal depots. Indeed, fat mass on day 19 was significantly higher than on day 15, when the five WAT depots were considered as a whole.

The adipocyte size in parametrial WAT of pregnant rats was measured at the times when resistin expression was highest and lowest. A representative microscopic image is shown in Fig. 4 which also shows that no change in adipocyte size took place between days 8 and 19 of pregnancy.
Figure 5 shows representative Northern blots of resistin mRNA at different times during pregnancy, together with their relative abundance - depicted as arbitrary units. Three depots were analysed, the parametrial, retroperitoneal and subcutaneous. A 10-15 times increase was observed in parametrial WAT in early pregnancy. By day 15 it was still 5-10 times higher but it was similar to non-pregnant rats by the end of pregnancy. A 3-5 times increase was also recorded by day 8 in retroperitoneal WAT but no differences from non-pregnant rats were evident by day 15. Subcutaneous WAT did not show any increase in resistin expression in early or mid pregnancy but underwent a reduction by day 19 .

Resistin expression was also analysed in tissues related to reproduction; namely, the placenta and mammary gland. The expression in these tissues was compared with that 
a.
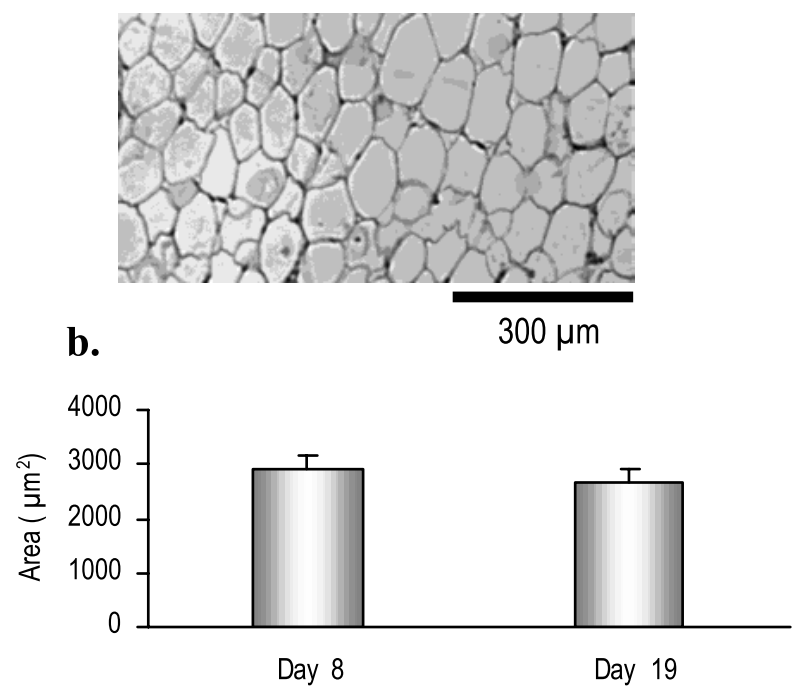

Figure 4 Adipocytes from parametrial WAT of pregnant rats in early and late pregnancy. (a) Representative microscopic image of adipocytes. Pieces of WAT were fixed in Bouin's fluid, dehydrated embedded in paraffin and stained. (b) Cell size of adipocytes. Bars represent the mean \pm S.E.M. of five to six rats, the value for each rat resulting from counting 150 cells. No differences were found by one-way ANOVA.

obtained in parametrial WAT. Results obtained are depicted in Fig. 6, showing levels of expression in parametrial WAT similar to levels in the placenta and mammary gland in pregnant rats at day 8 . However, by day 19 of pregnancy the expression in the placenta and mammary gland was significantly decreased with respect to WAT.

Resistin concentration was measured in plasma at different times during pregnancy and in both lactating and non-lactating dams. Pregnancy altered plasma resistin. By day 8 , the resistin concentration in pregnant rats was lower than that of non-pregnant ones but by days 15 and 19 of pregnancy it was higher (Table 1). During early lactation, plasma resistin remained higher (Table 2) but by day 22 post partum - and 1 day after weaning - plasma resistin was similar to that of non-pregnant rats.

CSF was obtained from non-pregnant and pregnant rats but no resistin was detected in CSF either by processing as it was collected or after lyophilisation and redilution in a 2 times smaller volume.

In an attempt to find systemic factors modulating resistin expression and considering that plasma hCG increases and peaks in early pregnancy, hCG was administered to a group of non-pregnant rats. It produced a statistically significant increase in resistin expression in parametrial WAT $24 \mathrm{~h}$ after injection (Fig. 7). However, no change in serum resistin was observed at that time (values not shown).

\section{a. Parametrial}

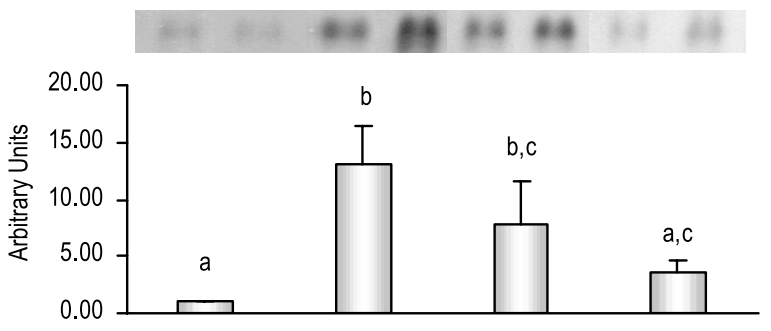

\section{b. Retroperitoneal}

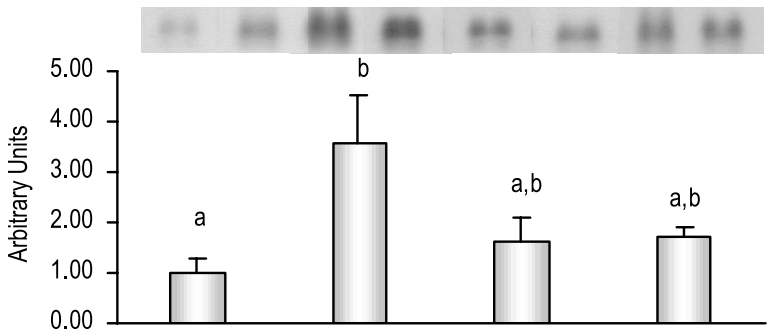

\section{c. Subcutaneous}

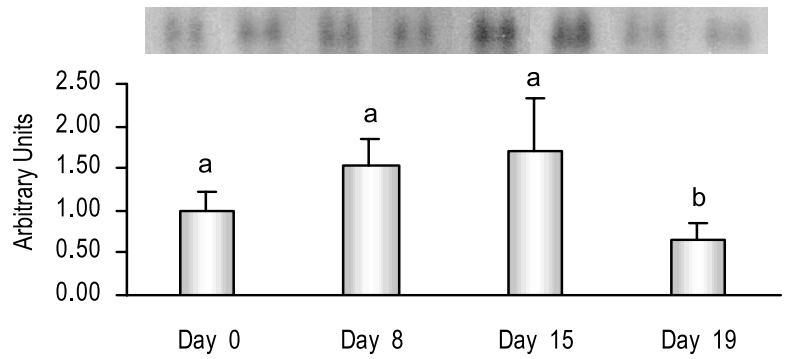

Figure 5 Resistin mRNA levels in different WAT depots of non-pregnant (day 0 ) and pregnant rats at different times during pregnancy. Fat pads were removed, RNA extracted and Northern blots probed for resistin mRNA and 18S rRNA. Representative blots of resistin mRNA are shown in each panel together with the relative abundance of mRNA. Bars represent the mean \pm S.E.M. of six to eight animals. Different superscript letters mean $P<0.05$ when analysed by a one-way ANOVA using the SNK test for post hoc comparisons.

\section{Discussion}

Discovered 4 years ago in rodent WAT (Holcomb et al. 2000), resistin has proven to be one of the most elusive adipokines. Initially proposed as an inhibitory adipogenesis factor (Kim et al. 2001) it was soon related to insulin resistance as a causative factor (Steppan et al. 2001). Pregnancy is a model of physiologically driven alterations in insulin sensitivity that changes from an enhanced state in the first third of pregnancy to a reduced one in the last third (Leturque et al. 1986, 1987). At the same time, an increase in WAT mass takes place during pregnancy 

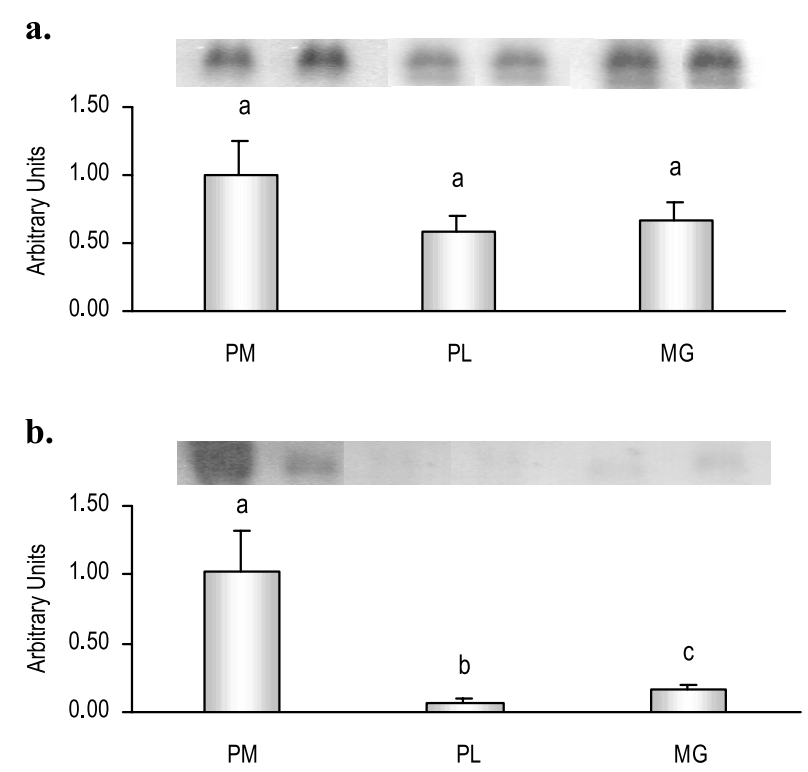

Figure 6 Resistin mRNA levels in parametrial (PM) WAT, placenta $(\mathrm{PL})$ and mammary gland $(\mathrm{MG})$ in (a) 8-day and (b) 19-day pregnant rats. Samples were removed, RNA extracted and Northern blots probed for resistin mRNA and $18 \mathrm{~S}$ rRNA. Representative blots of resistin mRNA are shown in each panel together with the relative abundance of mRNA. Bars represent the mean \pm S.E.M. of five to six animals. Different superscript letters mean $P<0.05$ when analysed by a one-way ANOVA using the SNK test for post hoc comparisons.

(Rocha et al. 2003). We measured resistin expression in three different WAT depots at three different times during pregnancy. A dramatic increase in resistin expression was found in parametrial (15 times) and in retroperitoneal (4 times) WAT depots by day 8 of pregnancy (Fig. 5). As pregnancy progressed, resistin expression decreased in both depots so that it was similar to that of non-pregnant controls at the end of pregnancy. Since resistin has been found to be expressed in organs other than WAT, i.e. in mouse pituitary (Morash et al. 2004), in the mammary gland (Steppan et al. 2001, Komatsu et al. 2003) and in the human placenta (Yura et al. 2003), we also analysed resistin expression in organs developed during pregnancy, namely, the placenta and the mammary gland (Fig. 6).

Table 1 Resistin plasma concentration during pregnancy in rats. Data are expressed as mean values \pm S.E.M. of six to eight animals

\section{Resistin (ng/ml)}

$\begin{array}{ll}\text { Day } 0 & 29 \cdot 5 \pm 1 \cdot 3^{\mathrm{a}} \\ \text { Day } 8 & 23 \cdot 6 \pm 2 \cdot 5^{\mathrm{b}} \\ \text { Day } 15 & 40 \cdot 0 \pm 1 \cdot 0^{\mathrm{c}} \\ \text { Day } 19 & 37 \cdot 3 \pm 2 \cdot 1^{\mathrm{c}}\end{array}$

Different superscript letters indicate $P<0 \cdot 05$ when analysed by a one-way ANOVA using the SNK test for post hoc comparisons.
Table 2 Resistin plasma concentration in dams either lactating or not lactating. Data are expressed as mean values \pm S.E.M. of three to four animals

\begin{tabular}{ll} 
& \multicolumn{1}{c}{ Resistin $(\mathrm{ng} / \mathrm{ml})$} \\
\cline { 2 - 2 } $\begin{array}{l}\text { Lactating dams } \\
\text { Day } 5 \text { post partum }\end{array}$ \\
$\begin{array}{l}\text { Non-lactating dams } \\
\text { Day } 22 \text { post partum } \\
\text { Day } 30 \text { post partum }\end{array}$ \\
$\begin{array}{l}\text { Different superscript letters indicate } P<0 \cdot 000 \text { when analysed by a one-factor } \\
\text { within-subject ANOVA with pair wise comparisons done by the Bonferroni } \\
\text { method. }\end{array}$
\end{tabular}

Resistin expression in both organs was as intense as that found in parametrial WAT by day 8 of pregnancy. However, it turned out to be much smaller than that of WAT by day 19. In other words, resistin expression in early pregnancy was very high in visceral WAT, the placenta and the mammary gland, showing similar levels of expression. As pregnancy progressed, it decreased, reaching basal levels by day 19 in WAT and even lower levels in the placenta and mammary gland. These results contrasted sharply with those obtained for plasma resistin in the same rats (Table 1). In fact, by day 8 of pregnancy when resistin expression was at its highest level - plasma concentration was even lower than in non-pregnant controls. On the other hand, by day 19 - when resistin expression had returned to pre-pregnancy levels - plasma resistin was dramatically enhanced.

We looked for an explanation for the different timecourse changes in resistin expression and plasma resistin by
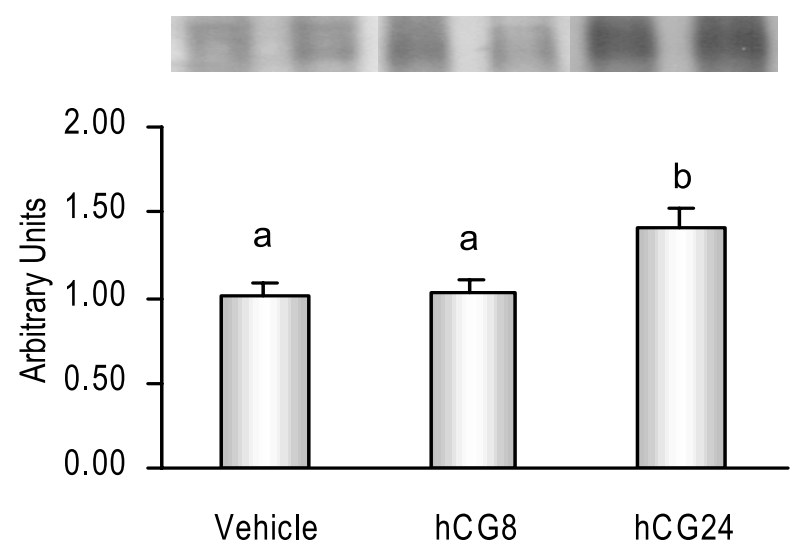

Figure 7 Resistin mRNA levels in parametrial WAT of non-pregnant rats after receiving a single dose of hCG at either $8 \mathrm{~h}$ (hCG8) or $24 \mathrm{~h}$ (hCG24) after injection. Fat pads were removed, RNA extracted and Northern blots probed for resistin mRNA and 18S rRNA. Representative blots of resistin mRNA are shown in each panel together with the relative abundance of mRNA. Bars represent the mean \pm S.E.M. of six to eight animals. Different superscript letters mean $P<0.05$ when analysed by a one-way ANOVA using the SNK test for post hoc comparisons. 
analysing the possible contribution of every organ studied to enhancing plasma resistin at the end of pregnancy. In the case of WAT, to explain the inconsistency between low resistin expression and high plasma resistin found in several models of obesity (Steppan et al. 2001, Way et al. 2001), it has been argued that plasma resistin reflects the total number of adipocytes while resistin mRNA is related to fat cell size (Steppan \& Lazar 2002). When we measured the mass of parametrial WAT (Fig. 3), we observed an increase between days 8 and 19 but no change in adipocyte size was recorded (Fig. 4). These observations implied a higher number of adipocytes in late pregnancy with no change in adipocyte size. The increase in plasma resistin in late pregnancy could be due, at least in part, to a higher number of adipocytes.

The contribution of the placenta to enhancing plasma resistin in late pregnancy is doubtful. In fact, although plasma resistin increased by days 15 and 19 of pregnancy, when the placenta is well developed, it remains enhanced 5 days post partum when the placenta was no longer present (Table 2). Opposite results have been found in humans, where both placenta expression and plasma resistin increase at the end of pregnancy, placenta expression being even higher than that of WAT (Sagawa et al. 2002, Ryan 2003, Yura et al. 2003).

The involvement of the mammary gland in the enhanced plasma resistin concentration in late pregnancy and during lactation is also uncertain. Although plasma resistin levels remained high in lactating dams and fell when suckling pups were separated from their mothers (Table 2), the expression in the mammary gland was so weak at the time of highest plasma levels that it is difficult to support a role for the mammary gland in enhancing plasma resistin concentration in late pregnancy and in lactating dams.

An alternative explanation that could reconcile the delayed peak in plasma resistin with peaks in expression could be either a long delay between synthesis and release or a reduced disappearance from serum (longer half-life) or both. Unfortunately, the present study did not deal with such possibilities. Moreover, this study does not rule out the contribution of other synthesising organs not considered in this work.

What might be the role of the increase in serum resistin in late pregnancy? Despite controversies about the role of resistin in governing insulin sensitivity, administration of resistin to male mice or rats induces insulin resistance (Steppan et al. 2001, Rajala et al. 2003). It seems, therefore, that the increase in serum resistin in late pregnancy could be a systemic signal to reduce insulin sensitivity, as found in this (Fig. 2) and previous studies. Moreover, plasma resistin remained elevated in lactating dams at peak lactation (day 5 post partum) when insulin sensitivity still remains diminished (Bell \& Bauman 1997).

What might be the role of the extremely high increase in resistin expression in visceral fat in early pregnancy?
There is evidence that resistin has an anti-adipogenic role both in vitro (Kim et al. 2001) and in vivo (Kim et al. 2004). This paper has shown that WAT mass does not increase during the first 15 days of pregnancy, except in the last week, despite a continuous increase in body weight (Figs 3 and 1 respectively). It has also shown that the adipocyte size in parametrial WAT does not differ between early and late pregnancy. This indicates a higher number of adipocytes at late pregnancy, i.e. adipocyte proliferation (Fig. 4). Thus, when resistin expression is greatly enhanced in visceral fat, no increase in fat mass takes place. These results are compatible with the anti-adipogenic role proposed for resistin. In short, it seems that in early pregnancy not only is there an increase in both food intake (Abelenda \& Puerta 1987, Rocha et al. 2003) and insulin sensitivity (Fig. 2) to allow maternal growth but an anti-adipogenic state also exists that prevents the deposition in the form of fat of the extra fuels ingested. This anti-adipogenic effect could be carried out by resistin acting locally. No role for the increased resistin expression in the placenta or mammary gland during early pregnancy was evident from the present results.

When we injected hCG into rats, an enhancement in WAT resistin expression was detected (Fig. 7), but no increase in serum resistin took place. Since hCG appears in plasma as soon as pregnancy begins and its concentration peaks in early pregnancy (Lenton et al. 1981), our results suggested that this hormone could enhance resistin expression at least in visceral fat, thus avoiding adipogenesis in early pregnancy. Later on, when hCG serum concentration falls, fat deposition for subsequent lactation could occur.

It has been hypothesised that resistin may be an adipose sensor for the nutritional state of animals since fasting reduces its expression in WAT while refeeding increases it (Kim et al. 2001, Steppan et al. 2001, Bertile \& Raclot 2004, Morash et al. 2004). Accordingly, it could be a signalling molecule for hypothalamic centres involved in energy balance maintenance. However, we were unable to detect resistin in CSF even when it was concentrated at twice its initial volume. This does not unequivocally prove the absence of resistin in CSF. However, it demonstrates that, if present, its concentration would be lower than in plasma, indicating some sort of regulation for resistin going to the central nervous system.

In conclusion, resistin expression is enhanced in rat visceral fat, the placenta and the mammary gland during early pregnancy when no increase in fat mass takes place. It is suggested that it could act in WAT locally as an adipogenesis suppressor. hCG administration enhances resistin expression in visceral fat and is suggested as the agent responsible for the detected increases. In contrast, serum resistin increases in the third week of pregnancy and remains elevated at peak lactation. It could be responsible for the reduced insulin sensitivity during both pregnancy and lactation. Resistin was not detected in CSF. 


\section{Acknowledegments}

We thank Dr Marta Torroba for her technical support in the histology and $\mathrm{Mr}$ Luis $\mathrm{M}$ Alonso and $\mathrm{Mr}$ Alfonso Cortés, from the Microscopy and Citometry Center, for their assistance in processing microscopic images. This work was supported by grants PR1/03-11658 from the Universidad Complutense de Madrid, 08·6/0013·1/2003 from the Comunidad de Madrid and BFI2003-01414 from Ministerio de Ciencia y Tecnologia, awarded to MP. The authors declare that there is no conflict of interest that would prejudice the impartiality of this scientific work.

\section{References}

Abelenda M \& Puerta M 1987 Inhibition of diet-induced thermogenesis during pregnancy in the rat. Pflïgers Archiv. European Journal of Physiology 409 314-317.

Banerjee RR, Rangwala SM, Shapiro JS, Rich AS, Rhoades B, Qi Y, Wang J, Rajala MW, Pocai A, Scherer PE et al. 2004 Regulation of fasted blood glucose by resistin. Science $\mathbf{3 0 3}$ 1195-1198.

Bell AW \& Bauman DE 1997 Adaptations of glucose metabolism during pregnancy and lactation. Journal of Mammary Gland Biology and Neoplasia 2 265-278.

Bertile F \& Raclot T 2004 Differences in mRNA expression of adipocyte-derived factors in response to fasting, refeeding and leptin. Biochimica et Biophysica Acta 1683 101-109.

Bing C, Gomez-Ambrosi J, Zabalegui N, Williams G \& Trayhurn P 2002 Resistin and RELM-alpha gene expression in white adipose tissue of lactating mice. Biochemical and Biophysical Research Communications 296 458-462.

Bonora E, Moghetti P, Zancanaro C, Cigolini M, Querena M, Cacciatori V, Corgnati A \& Muggeo M 1989 Estimates of in vivo insulin action in man: comparison of insulin tolerance tests with euglycemic and hyperglycemic glucose clamp studies. Journal of Clinical and Endocrinological Metabolism 68 374-378.

Chen L \& Nyomba BL 2003 Glucose intolerance and resistin expression in rat offspring exposed to ethanol in utero: modulation by postnatal high-fat diet. Endocrinology 144 500-508.

Chomczynski P \& Sacchi N 1987 Single-step method of RNA isolation by acid guanidinium thiocyanate-phenol-chloroform extraction. Analytical Biochemistry 162 156-159.

Frühbeck G, Gómez-Ambrosi J, Muruzábal FJ \& Burrell AM 2001 The adipocyte: a model for integration of endocrine and metabolic signaling in energy metabolism regulation. American Journal of Physiology - Endocrinology and Metabolism 280 E827-E847.

Fujita H, Fujishima H, Morii T, Koshimura J, Narita T, Kakei M \& Ito $\mathrm{S} 2002$ Effect of metformin on adipose tissue resistin expression in $\mathrm{db} / \mathrm{db}$ mice. Biochemical and Biophysical Research Communications $298345-349$

Gomez-Ambrosi J, Zabalegui N, Bing C, Tisdale MJ, Trayhurn P \& Williams G 2002 Weight loss in tumour-bearing mice is not associated with changes in resistin gene expression in white adipose tissue. Hormone and Metabolic Research 34 674-677.

Guerre-Millo M 2004 Adipose tissue and adipokines: for better or worse. Diabetes and Metabolism 30 13-19.

Haugen F, Jorgensen A, Drevon CA \& Trayhurn P 2001 Inhibition by insulin of resistin gene expression in 3T3-L1 adipocytes. FEBS Letters 507 105-108.

Herrera E, Lasunción MA, Huerta L \& Martin-Hidalgo A 2000 Plasma leptin levels in rat mother and offspring during pregnancy and lactation. Biology of the Neonate 78 315-320.
Holcomb IN, Kabakoff RC, Chan B, Baker TW, Gurney A, Henzel W, Nelson C, Lowman HB, Wright BD, Skelton NJ et al. 2000 FIZZ1, a novel cysteine-rich secreted protein associated with pulmonary inflammation, defines a new gene family. EMBO Journal 19 4046-4055.

Juan CC, Au LC, Fang VS, Kang SF, Ko YH, Kuo SF, Hsu YP, Kwok CF \& Ho LT 2001 Suppressed gene expression of adipocyte resistin in an insulin-resistant rat model probably by elevated free fatty acids. Biochemical and Biophysical Research Communications 289 $1328-1333$

Kim KH, Lee K, Moon YS \& Sul HS 2001 A cysteine-rich adipose tissue-specific secretory factor inhibits adipocyte differentiation. Journal of Biological Chemistry 276 11252-11256.

Kim KH, Zhao L, Moon Y, Kang C \& Sul HS 2004 Dominant inhibitory adipocyte-specific secretory factor (ADSF)/resistin enhances adipogenesis and improves insulin sensitivity. PNAS 101 $6780-6785$

Komatsu T, Itoh F, Mikawa S \& Hodate K 2003 Gene expression of resistin in adipose tissue and mammary gland of lactating and non-lactating cows. Journal of Endocrinology 178 R1-R5.

Le Lay S, Boucher J, Rey A, Castan Laurell I, Krief S, Ferre P, Valet P \& Dugail I 2001 Decreased resistin expression in mice with different sensitivities to a high-fat diet. Biochemical and Biophysical Research Communications 289 564-567.

Lenton EA, Grudzinskas GJ, Neal LM, Chard T \& Cooke ID 1981 Chorionic gonadotropin concentration in early human pregnancy: comparison of specific and nonspecific assays. Fertility and Sterility 35 $40-45$.

Leturque A, Ferré P, Burnol AF, Kande J, Maulard P \& Girard J 1986 Glucose utilization rates and insulin sensitivity in vivo in tissues of virgin and pregnant rats. Diabetes 35 172-177.

Leturque A, Hauguel S, Ferré P \& Girard J 1987 Glucose metabolism in pregnancy. Biology of the Neonate 51 64-69.

Lundbaek K 1962 Intravenous glucose tolerance as a tool in definition and diagnosis of diabetes mellitus. British Medical Journal $\mathbf{5 2 9 1}$ $1507-1513$

Milan G, Granzotto M, Scarda A, Calcagno A, Pagano C, Federspil G \& Vettor R 2002 Resistin and adiponectin expression in visceral fat of obese rats: effect of weight loss. Obesity Research 10 1095-1103.

Moore GBT, Chapman H, Holder JC, Lister CA, Piercy V, Smith SA \& Clapham JC 2001 Differential regulation of adipocytokine mRNAs by rosiglitazone in $d b / d b$ mice. Biochemical and Biophysical Research Communications 286 735-741.

Morash BA, Ur E, Wiesner G, Roy J \& Wilkinson M 2004 Pituitary resistin gene expression: effects of age, gender and obesity. Neuroendocrinology 79 149-156.

Puerta M, Abelenda M, Rocha M \& Trayhurn P 2002 Effect of acute cold exposure on the expression of the adiponectin, resistin and leptin genes in rat white and brown adipose tissues. Hormone and Metabolic Research 34 629-634.

Rajala MW, Obici S, Scherer PE \& Rossetti L 2003 Adipose-derived resistin and gut-derived resistin-like molecule-beta selectively impair insulin action on glucose production. Journal of Clinical Investigation 111 225-230.

Rocha M, Bing C, Williams G \& Puerta M 2003 Pregnancy-induced hyperphagia is associated with increased gene expression of hypothalamic agouti-related peptide in rats. Regulatory Peptides 114 159-165.

Ryan EA 2003 Hormones and insulin resistance during pregnancy. Lancet 362 1777-1778.

Sagawa N, Yura S, Itoh H, Mise H, Kakui K, Korita D, Takemura M, Nuamah MA, Ogawa Y, Masuzaki H et al. 2002 Role of leptin in pregnancy - a review. Placenta 23 (Suppl A) S80-S86.

Shojima N, Sakoda H, Ogihara T, Fujishiro M, Katagiri H, Anai M, Onishi Y, Ono H, Inukai K, Abe M et al. 2002 Humoral regulation of resistin expression in 3T3-L1 and mouse adipose cells. Diabetes 51 1737-1744. 
Steppan CM \& Lazar MA 2002 Resistin and obesity-associated insulin resistance. Trends in Endocrinology and Metabolism 13 18-23.

Steppan CM, Bailey ST, Bhat S, Brown EJ, Banerjee RR, Wright CM, Patel HR, Ahima RS \& Lazar MA 2001 The hormone resistin links obesity to diabetes. Nature 409 307-312.

Trayhurn P \& Beattie JH 2001 Physiological role of adipose tissue: white adipose tissue as an endocrine and secretory organ. Proceedings. of the Nutrition Society 60 329-339.

Trayhurn P, Duncan JS, Nestor A, Thomas MEA \& Rayner DV 1994 Chemiluminescent detection of mRNAs on northern blots with digoxigenin end-labelled oligonucleotides. Analytical Biochemistry 222 224-230.

Trayhurn P, Duncan JS \& Rayner DV 1995 Acute cold-induced suppression of $o b$ (obese) gene expression in white adipose tissue of mice: mediation by the sympathetic system. Biochemical Journal 311 729-733.
Way JM, Görgüm CZ, Tong Q, Uysal KT, Brown KK, Harrintong WW, Oliver WO Jr, Willson TM, Kliewer SA \& Hotamisligil GS 2001 Adipose tissue resistin expression is severely suppressed in obesity and stimulated by peroxisome proliferator-activated receptor $\mathrm{g}$ agonists. Journal of Biological Chemistry 276 25651-25653.

Yura S, Sagawa N, Itoh H, Kakui K, Nuamah MA, Korita D, Takemura M \& Fujii S 2003 Resistin is expressed in the human placenta. Journal of Clinical Endocrinology and Metabolism $\mathbf{8 8}$ 1394-1397.

Received in final form 21 February 2005

Accepted 25 February 2005

Made available online as an

Accepted Preprint 2 March 2005 